\title{
Widespread magmatic activities on the angrite parent body at 4562 Ma ago
}

\author{
Naoji Sugiura $^{1}$, Akiko Miyazaki $^{1}$, and Keizo Yanai ${ }^{2}$ \\ ${ }^{1}$ Department of Earth and Planetary Science, University of Tokyo, Japan \\ ${ }^{2}$ Department of Civil and Environmental Engineering, Iwate University, Japan
}

(Received May 18, 2005; Revised July 26, 2005; Accepted July 27, 2005)

\begin{abstract}
Mn-Cr chronology of four quenched angrites showed that they formed nearly at the same time (4562 Ma) on the surface of the parent-body. Based on the chemical compositions, the cosmic ray exposure ages, and considerations on the thermal history of an achondrite parent-body, we suggest that the four angrites formed on top of a shallow magma ocean on the angrite parent body.
\end{abstract}

Key words: Age, angrites, Mn-Cr dating, SIMS.

\section{Introduction}

Age determination of angrites is important because the angrites LEW86010 and Angra dos Reis are used as an anchor for connecting $\mathrm{Pb}-\mathrm{Pb}$ absolute ages $(4557.8 \pm 0.5 \mathrm{Ma}$, Lugmair and Galer, 1992) and $\mathrm{Mn}-\mathrm{Cr}$ ages $\left({ }^{53} \mathrm{Mn} /{ }^{55} \mathrm{Mn}=\right.$ $(1.25 \pm 0.07) \times 10^{-6}$, Lugmair and Shukolyukov, 1998) and because igneous activities on the angrite parent body are yet poorly understood.

Recently, several new angrites were found. Among them, D'Orbigny is the largest and best studied both petrologically (Mittlefehldt et al., 2002) and chronologically (Nyquist et al., 2003; Glavin et al., 2004). The ${ }^{53} \mathrm{Mn} /{ }^{55} \mathrm{Mn}$ initial ratio for D'Orbigny reported by Glavin et al. (2004) is $(3.24 \pm 0.04) \times 10^{-6}$, which appears to be slightly inconsistent with that $(2.83 \pm 0.25) \times 10^{-6}$ reported by Nyquist et al. (2003). In any case, D'Orbigny is nearly 5 Ma older than LEW86010 and Angra dos Reis (Glavin et al., 2004). The $\mathrm{Pb}-\mathrm{Pb}$ age of D'Orbigny was initially reported to be $4557 \pm 1$ Ma: (Jagoutz et al., 2003) and nearly identical with those of LEW86010 and Angra dos Reis (4557.8 Ma: Lugmair and Shukolyukov, 1998). But recent reevaluation of the $\mathrm{Pb}-\mathrm{Pb}$ data of $\mathrm{D}$ 'Orbigny has resulted in an age of $4563 \pm 1 \mathrm{Ma}$ (referred in Spivak-Birndorf et al., 2005). Therefore, the $\mathrm{Mn}-\mathrm{Cr}$ and the $\mathrm{Pb}-\mathrm{Pb}$ ages of these three angrites are in excellent agreement with each other. Excess ${ }^{26} \mathrm{Mg}$ due to decay of ${ }^{26} \mathrm{Al}$ was detected in D'Orbigny (Nyquist et al., 2003; Spivak-Birndorf et al., 2005) confirming old ages of this angrite.

Here we report $\mathrm{Mn}-\mathrm{Cr}$ ages of four angrites measured by secondary ion mass spectrometry (SIMS). Preliminary reports in abstract form of this study have been published as Sugiura (2002) and Sugiura et al. (2003).

\section{Samples and Experimental Procedures}

Four angrites (D’Orbigny, Sahara 99555, Asuka 881371 and Northwest Africa (NWA) 1670) were examined. Petro-

Copy right(c) The Society of Geomagnetism and Earth, Planetary and Space Sciences (SGEPSS); The Seismological Society of Japan; The Volcanological Society of Japan; The Geodetic Society of Japan; The Japanese Society for Planetary Sciences; TERRAPUB. logic description of the Asuka 881371 has been reported by Yanai (1994) and by Mikouchi et al. (1996). Petrology and chemistry of D'Orbigny and chemistry of Sahara 99555 have been reported by Mittlefehldt et al. (2002). Petrology of NWA1670 has been reported by Mikouchi et al. (2003). Generally, these four angrites appear to have cooled more rapidly than LEW86010 and Angra dos Reis. They are called as "quenched angrites" by Mikouchi et al. (2003). Burial depth of less than $0.5 \mathrm{~m}$ was suggested for D’Orbigny and Asuka 881371 (Mikouchi et al., 2001). Because of the finer grain size of NWA 1670 than that of the other angrites, its burial depth was probably much shallower than $0.5 \mathrm{~m}$.

Polished sections of the four angrites were examined with a Scanning Electron Microscope (SEM) and Mn-rich, Crpoor spots in olivine were selected for SIMS measurements. $\mathrm{Fe}$-poor olivines having low $\mathrm{Mn} / \mathrm{Cr}$ ratios were also measured to precisely determine the $y$-intercept of isochron.

An ion probe (IMF-6f) at Univ. of Tokyo was used for the $\mathrm{Mn}-\mathrm{Cr}$ measurements. An intense O-primary beam ( $~ 5$ $\mathrm{nA}, \sim 30 \mu \mathrm{m}$ in diameter) was used for sputtering. Secondary ions $\left({ }^{52} \mathrm{Cr}^{+},{ }^{53} \mathrm{Cr}^{+}\right.$and $\left.\mathrm{Mn}^{+}\right)$were accelerated with $10 \mathrm{kV}$. The mass resolving power was set to $\sim 4500$. Isotope anomaly of ${ }^{53} \mathrm{Cr}$ is expressed as $\delta^{53} \mathrm{Cr}$ which is defined as permil deviation from the ${ }^{53} \mathrm{Cr} /{ }^{52} \mathrm{Cr}$ of terrestrial materials. Instrumental isotopic fractionation was assumed to be nearly constant for this study. This is because ${ }^{50} \mathrm{Cr}$ cannot be measured accurately due to severe ${ }^{50} \mathrm{Ti}$ interference and hence cannot be used for monitoring instrumental isotopic fractionation. According to our previous experience on $\mathrm{Mn}-\mathrm{Cr}$ measurements of iron meteorites, the deviation of instrumental isotopic fractionation of $\delta^{53} \mathrm{Cr}$ is $\sim 1.9 \%$ (Sugiura and Hoshino, 2003) and is insignificant compared with large isotopic signals due to decay of ${ }^{53} \mathrm{Mn}$, though this deviation is propagated to the reported errors. The $\mathrm{Mn} / \mathrm{Cr}$ relative sensitivity (defined as $\left(\mathrm{Mn}^{+} / \mathrm{Cr}^{+}\right) /([\mathrm{Mn}] /[\mathrm{Cr}])$ where $[\mathrm{Mn}] /[\mathrm{Cr}]$ represents the atomic ratio in target materials) for $\mathrm{Fe}$ - and Ca-rich olivine was estimated to be $1.62 \pm 0.12(2 \sigma)$ from measurements of synthetic glass samples that have bulk compositions similar to the $\mathrm{Fe}$ - and $\mathrm{Ca}$-rich olivine 

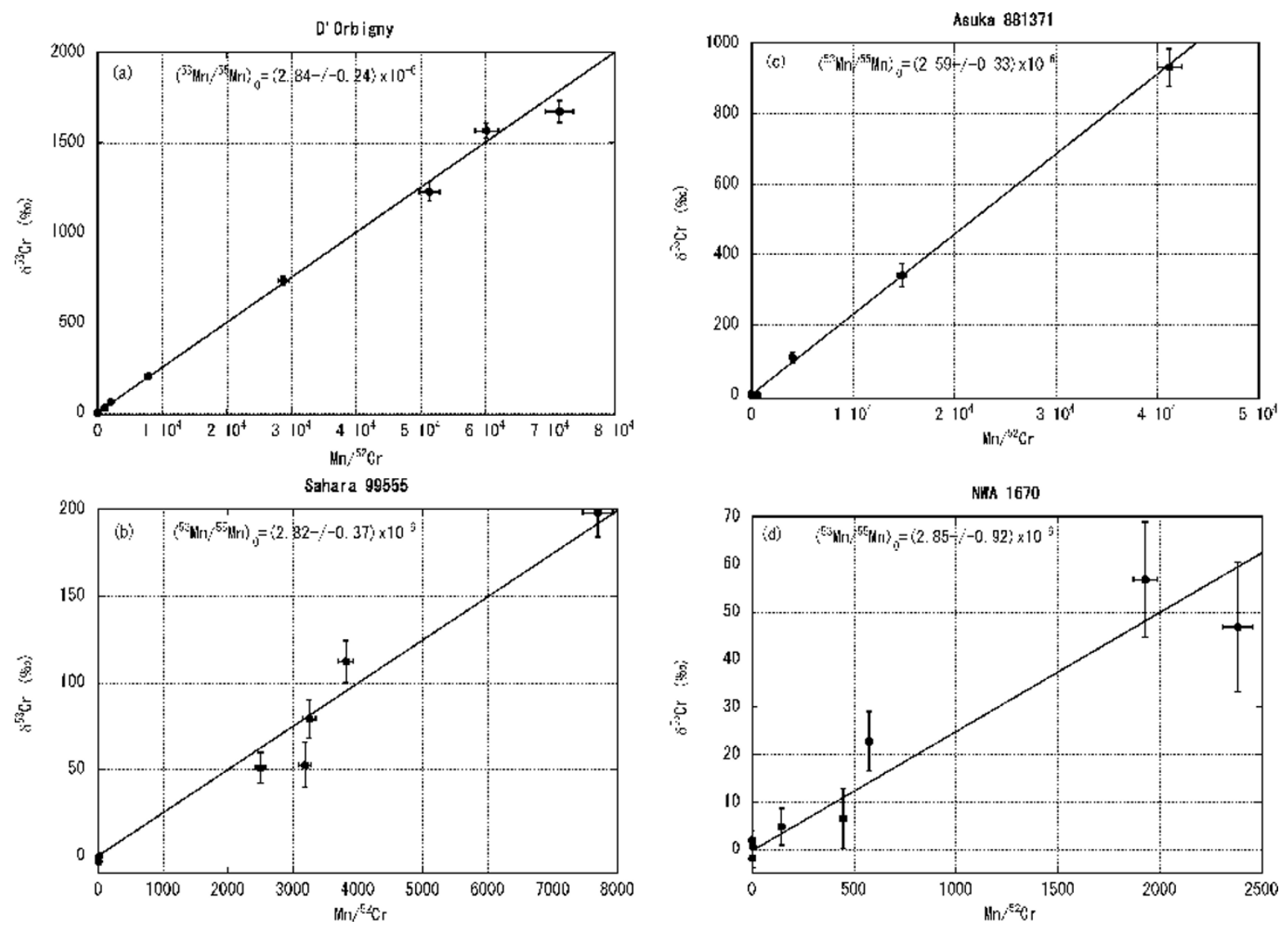

Fig. 1. Isochron diagrams for (a) D’Orbigny, (b) Sahara 99555, (c) Asuka 881371 and (d) NWA 1670 . The error bars are $1 \sigma$. The errors attached to the initial $\mathrm{Mn}$ ratios are $2 \sigma$ error including uncertainty of the relative sensitivity factor.

Table 1. Initial Mn ratios, ages before LEW 86010 and cosmic ray exposure ages (CREA) for four angrites.

\begin{tabular}{cccccc}
\hline & ${ }^{53} \mathrm{Mn} /{ }^{55} \mathrm{Mn}$ & $2 \sigma$ error-1 & $2 \sigma$ error-2 & Age before LEW 86010* & CREA \\
\hline D’Orbigny & $2.84 \times 10^{-6}$ & $0.12 \times 10^{-6}$ & $0.24 \times 10^{-6}$ & $4.4 \pm 0.5 \mathrm{Ma}$ & $11 \mathrm{Ma}^{* *}$ \\
Sahara 99555 & $2.82 \times 10^{-6}$ & $0.30 \times 10^{-6}$ & $0.37 \times 10^{-6}$ & $4.4 \pm 0.7 \mathrm{Ma}$ & $6.1 \mathrm{Ma}^{* *}$ \\
Asuka 881371 & $2.59 \times 10^{-6}$ & $0.26 \times 10^{-6}$ & $0.33 \times 10^{-6}$ & $3.9 \pm 0.7 \mathrm{Ma}$ & $5.3 \mathrm{Ma}^{* *}$ \\
NWA 1670 & $2.85 \times 10^{-6}$ & $0.89 \times 10^{-6}$ & $0.92 \times 10^{-6}$ & $4.4 \pm 1.8 \mathrm{Ma}$ & $\sim 15 \mathrm{Ma}^{* * *}$ \\
\hline
\end{tabular}

$2 \sigma$ error- 1 includes only the statistical deviation around the isochron.

$2 \sigma$ error- 2 includes the statistical deviation and the uncertainty of the relative sensitivity factor.

*Initial ratio for LEW 86010 is $1.25 \times 10^{-6}$ from Lugmair and Shukolyukov (1998). The errors correspond to the $2 \sigma$ error-2 of the

${ }^{53} \mathrm{Mn} /{ }^{55} \mathrm{Mn}$ initial ratios. The absolute age of the LEW 86010 is $4557.8 \pm 0.5 \mathrm{Ma}$ (Lugmair and Galer, 1992).

** Kurat et al. (2004) and references therein.

**** Miura et al. (2004).

in the angrites. The synthetic sample contains $\sim 0.34 \mathrm{wt} \%$ $\mathrm{Cr}_{2} \mathrm{O}_{3}$ and $\sim 0.92$ wt $\% \mathrm{MnO}$ which were determined by EPMA (JEOL JXA-8800).

\section{Results}

The $\delta^{53} \mathrm{Cr}$ vs. $\mathrm{Mn} /{ }^{52} \mathrm{Cr}$ diagrams for the four angrites are shown in Fig. 1. (The results are summarized in the supplementary table.) The ${ }^{53} \mathrm{Cr}$ isotope anomalies are well correlated with the $\mathrm{Mn} / \mathrm{Cr}$ ratios, suggesting that they are due to in situ decay of ${ }^{53} \mathrm{Mn}$. The inferred initial ${ }^{53} \mathrm{Mn} /{ }^{55} \mathrm{Mn}$ ratios are given in Table 1 . The ${ }^{53} \mathrm{Cr}$ isotope anomalies are large and hence a slight change in the instrumental isotope fractionation is insignificant. The highest $\mathrm{Mn} /{ }^{52} \mathrm{Cr}$ ratio for an angrite ranges from 2400 for NWA 1670 to $7 \times 10^{4}$ for D'Orbigny. The relatively small ratio for NWA 1670 is probably due to the extremely fast cooling rate of this angrite that presumably caused a smaller degree of $\mathrm{Cr}$ fractionation during the solidification. The high $\mathrm{Mn} /{ }^{52} \mathrm{Cr}$ ratio for D'Orbigny is partly due to a low bulk $\mathrm{Cr}$ concentration in D'Orbigny (Mittlefehldt et al., 2002). But the extremely high $\mathrm{Mn} /{ }^{52} \mathrm{Cr}$ ratio may suggest that the cooling rate of this angrite was slower than those of the other angrites. These $\mathrm{Mn} /{ }^{52} \mathrm{Cr}$ ratios obtained by SIMS are more than two orders of magnitude larger than those obtained by mineral separation (Nyquist et al., 2003). For angrites with large $\mathrm{Mn} /{ }^{52} \mathrm{Cr}$ ratios and large excesses in ${ }^{53} \mathrm{Cr}$, the initial $\mathrm{Mn}$ isotope ratios were determined precisely. Two kinds of errors are reported in Table 1. Error-1 is calculated from the scatter of data points around the isochron. Error- 2 includes the uncertainty of the estimated relative sensitivity factor in addi- 
tion to the error-1. For comparison of the initial Mn isotope ratios within the present data-set, error-1 should be used, whereas for comparison of the present data with those reported by other workers, error- 2 should be used. The initial ratios for the four angrites (Table 1) are identical within the $2 \sigma$ errors.

We note that the inferred ${ }^{53} \mathrm{Mn} /{ }^{55} \mathrm{Mn}$ initial ratio for D'Orbigny agrees quite well with that $(2.83 \pm 0.25) \times 10^{-6}$ reported by Nyquist et al. (2003). The initial ratio reported by Glavin et al. (2004) is $(3.24 \pm 0.04) \times 10^{-6}$ and is apparently inconsistent with the present result. However, the error given by Glavin et al. (2004) appears not to include $5 \%$ uncertainty of the concentration measurements. If this uncertainty is propagated to the error of their initial ratio, then the result of Glavin et al. (2004) is also consistent with the present result. Nyquist et al. (2003) reported that data for Sahara 99555 are in agreement with the D'Orbigny isochron. The present data for Sahara 99555 are also consistent with their report.

\section{Discussion}

It is obvious that four angrites have essentially the same initial ${ }^{53} \mathrm{Mn} /{ }^{55} \mathrm{Mn}$ ratios, and they are about $4 \mathrm{Ma}$ older than LEW 86010 and Angra dos Reis. A common petrologic feature of these four angrite is the fast cooling rate compared with LEW 86010 and Angra dos Reis. In particular, the NWA 1670 seems to have cooled very rapidly at the very surface of the parent-body. Therefore, the identical $\mathrm{Mn}-\mathrm{Cr}$ ages for the four angrites probably reflect the age of the initial cooling from the magmatic temperature.

Cosmic ray exposure ages of the four angrites are known (Table 1). Asuka 881371 and Sahara 99555 may have been ejected from the parent body by the same event, because the difference in the exposure ages is small. But it is clear that the four quenched angrites studied here were ejected by at least 3 different events. In addition, LEW 87051, another quenched angrite that was not studied here, has a very short cosmic ray exposure age $(\sim 0.2 \mathrm{Ma}$, Eugster and Weigel, 1995) and hence must have been ejected by an event unrelated to the ejection of the four angrites studied here. This suggests that quenched angrites are a major population on the angrite parent body.

According to the bulk chemical compositions reported by Mittlefehldt et al. (2002), D'Orbigny and Sahara 99555 are similar and they are slightly different from Asuka 881371. In particular, the $\mathrm{Mg} /(\mathrm{Mg}+\mathrm{Fe})$ ratios and bulk $\mathrm{Cr}$ concentrations in D'Orbigny and Sahara 99555 seem to be significantly different from those in Asuka 881371. (No bulk chemical data are available for NWA 1670, yet.) Therefore, combining the cosmic ray exposure age data, the bulk chemical data and the $\mathrm{Mn}-\mathrm{Cr}$ age data, it appears that the four quenched angrites were derived from four different lava flows that solidified nearly at the same time, near the surface of the angrite parent body. Absence of quenched angrites of other ages means that magmatic activities on the surface of angrite parent body occurred only briefly at 4562 Ma ago but it was wide spread on the parent body. Angra dos Reis and LEW 86010 cooled slowly somewhere in the deeper part of the parent-body, recording the $\mathrm{Pb}-\mathrm{Pb}$ age of $\sim 4558$ Ma.
Simulations of thermal histories of achondrite parent bodies with a ${ }^{26} \mathrm{Al}$ heat source have been made (e.g. Ghosh and McSween, 1998). According to these studies, a small asteroidal body (radius $\sim 10 \mathrm{~km}$ ) could be molten if they accreted within $\sim 2 \mathrm{Ma}$ after the formation of CAIs and reaches a peak temperature at $\sim 4 \mathrm{Ma}$ after CAIs. If the partial melt migrates to the surface, then a magma ocean is formed on the parent body. Al-Mg dating of D'Orbigny and Sahara 99555 by Nyquist et al. (2003) and by SpivakBirndorf et al. (2005) showed that the quenched angrites formed $\sim 5 \mathrm{Ma}$ after the CAI formation. Therefore, the quenched angrites may have formed by eruption on top of the cooling magma ocean. As discussed by Ghosh and McSween (1998), a partial melt in such a parent body is enriched in Al relative to the bulk asteroidal composition and temperatures can reach $1600 \mathrm{~K}$ or higher. Volatile elements like $\mathrm{K}$ and $\mathrm{Na}$ may have escaped from the shallow magma ocean by evaporation, resulting in the extreme depletion of these elements in the angrites (Mittlefehldt et al., 2002).

Because of the very fast cooling rates of quenched angrites, some workers (Jurewicz et al., 1993; Mikouchi et al., 1996) suggested that they formed as impact melts. However, it is rather unlikely that four samples are derived from a single impact melt and only two samples are derived from the rest of the parent body. It seems more likely that the quenched angrites were derived from a magma ocean that covered the entire surface of the parent body. It is possible to consider that many quenched angrites were produced by different impact events. But this scenario does not explain why impact melting has to happen only during a restricted period of time, as we know that heavy bombardment continued for several hundreds of million years in the inner solar system.

One may prefer to consider that ordinary volcanic activities produced angrites rather than proposing a magma ocean. However, REE abundance patterns of quenched angrites are very similar (Floss et al., 2003) suggesting that they crystallized from very similar magmas. Each volcano is supposed to have a separate magma chamber that is produced by partial melting and in which fractional crystallization may occur. Therefore, we think that volcanic rocks derived from different volcanoes may show wider scatter in the REE abundance patterns. Also, as discussed recently by Greenwood et al. (2005), oxygen isotopic compositions of angrites are completely homogenized, suggesting complete melting and hence formation of a magma ocean on the angrite parent body. Altogether, we think that formation of quenched angrites on top of a magma ocean is quite probable and more likely than other mechanism of angrite formation.

\section{Conclusions}

$\mathrm{Mn}-\mathrm{Cr}$ chronology of four quenched angrites showed that they formed nearly at the same time (4562 Ma) on the surface of the parent-body. Based on the chemical compositions, the cosmic ray exposure ages, and considerations on the thermal history of an achondrite parent-body, we suggest that the four angrites formed on top of a shallow magma ocean on the angrite parent body. 
Acknowledgments. The authors would like to thank the National Institute of Polar Research for providing a valuable sample. Dr. K. Hashizume kindly helped calibration experiments. Careful reviews by Drs. N. T. Kita and N. Yurimoto greatly improved this manuscript. Dr. E. Jagoutz kindly supplied up to date information on the $\mathrm{Pb}-\mathrm{Pb}$ dating of D'Orbigny. This work was supported by grants-in-aid of science research (14340169) from the Japanese Society for the Promotion of Science.

\section{Appendix.}

Supplementary Table. Mn-Cr systematics in four angrites.

\begin{tabular}{|c|c|c|c|}
\hline & $\mathrm{Mn} /{ }^{52} \mathrm{Cr}$ & $\delta^{53} \mathrm{Cr}(\% o)$ & $\delta^{53} \mathrm{Cr}$ error $(\% o)$ \\
\hline \multicolumn{4}{|l|}{ D’Orbigny } \\
\hline & $2.04 \mathrm{E}+03$ & 61.4 & 7.5 \\
\hline & $9.50 \mathrm{E}+00$ & -1.8 & 2.1 \\
\hline & $7.85 \mathrm{E}+03$ & 201.5 & 11.1 \\
\hline & $6.02 \mathrm{E}+04$ & 1565 & 43 \\
\hline & $5.14 \mathrm{E}+04$ & 1227 & 53 \\
\hline & $7.15 \mathrm{E}+04$ & 1671 & 60 \\
\hline & $1.12 \mathrm{E}+03$ & 26.0 & 5.2 \\
\hline & $2.88 \mathrm{E}+04$ & 734.1 & 26.0 \\
\hline \multicolumn{4}{|l|}{ Sahara 99555} \\
\hline & $3.19 \mathrm{E}+03$ & 52.5 & 12.8 \\
\hline & $2.50 \mathrm{E}+03$ & 50.8 & 8.7 \\
\hline & $1.00 \mathrm{E}+01$ & -3.0 & 1.1 \\
\hline & $1.01 \mathrm{E}+01$ & -0.8 & 1.1 \\
\hline & $1.92 \mathrm{E}+01$ & -0.2 & 1.2 \\
\hline & $3.26 \mathrm{E}+03$ & 79.1 & 10.9 \\
\hline & $3.82 \mathrm{E}+03$ & 112.2 & 12.1 \\
\hline & $7.70 \mathrm{E}+03$ & 198.2 & 13.9 \\
\hline \multicolumn{4}{|l|}{ Asuka 881371} \\
\hline & $7.68 \mathrm{E}+02$ & 0.3 & 6.0 \\
\hline & $8.60 \mathrm{E}+00$ & 2.1 & 1.2 \\
\hline & $5.55 \mathrm{E}+04$ & 932.0 & 53.2 \\
\hline & $5.45 \mathrm{E}+03$ & 107.0 & 15.2 \\
\hline & $5.20 \mathrm{E}+00$ & -1.8 & 1.0 \\
\hline & $2.00 \mathrm{E}+04$ & 340.0 & 31.6 \\
\hline & $7.30 \mathrm{E}+00$ & -0.1 & 1.2 \\
\hline \multicolumn{4}{|l|}{ NWA 1670} \\
\hline & $8.00 \mathrm{E}-01$ & 2.0 & 0.7 \\
\hline & $2.00 \mathrm{E}+00$ & -1.8 & 0.7 \\
\hline & $1.95 \mathrm{E}+02$ & 4.8 & 3.4 \\
\hline & $7.72 \mathrm{E}+02$ & 22.8 & 6.0 \\
\hline & $2.60 \mathrm{E}+03$ & 56.7 & 12.0 \\
\hline & $6.03 \mathrm{E}+02$ & 6.5 & 5.9 \\
\hline & $3.80 \mathrm{E}+00$ & 0.6 & 0.5 \\
\hline & $3.21 \mathrm{E}+03$ & 46.8 & 13.4 \\
\hline
\end{tabular}

\section{References}

Eugster, O. and A. Weigel, Multiple break-up of the angrite parent asteroid: Asuka 881371 and other angrites (abstr), Meteoritics, 30, 504, 1995.

Floss, C., G. Crozaz, G. McKay, T. Mikouchi, and M. Killgore, Petrogenesis of angrites, Geochim. Cosmochim. Acta, 67, 4775-4789, 2003.

Ghosh, A. and H. Y. McSween, Jr., A thermal model for the differentiation of asteroid 4 Vesta, based on radiogenic heating, Icarus, 134, 187-206, 1998

Glavin, D. P., A. Kubny, E. Jagoutz, and G. W. Lugmair, Mn-Cr isotope systematics of the D’Orbigny angrite, Meteoritics \& Planetary Sci., 39 693-700, 2004.

Greenwood, R. C., I. A. Franchi, A. Jambon, and P. C. Buchanan, Widespread magma oceans on asteroidal bodies in the early solar system, Nature, 916-918, 2005.

Jagoutz, E., R. Jotter, A. Kubny, M. E. Varela, R. Zartman, G. Kurat, and G. W. Lugmair, $\mathrm{Cm}$ ?-U-Th-Pb isotopic evolution of the D'Orbigny angrite, Meteoritics \& Planetary Sci., 38, A81, 2003.

Jurewicz, A. G., D. W. Mittlefehldt, and J. H. Jones, Experimental partial melting of the Allende (CV) and Murchison (CM) chondrites and the origin of asteroidal basalts, Geochim. Cosmochim. Acta, 57, 2123-2139, 1993

Kurat, G., M. E. Varela, F. Brandstatter, G. Weckwerth, R. N. Clayton, H. W. Weber, and D'Orbigny, A non-igneous angritic achondrite? Geochim. Cosmochim. Acta, 68, 1901-1921, 2004.

Lugmair, G. W. and S. J. G. Galer, Age and isotopic relationships among the angrites Lewis Cliff 86010 and Angra dos Reis, Geochim. Cosmochim. Acta, 56, 1673-1694, 1992.

Lugmair, G. W. and A. Shukolyukov, Early solar system timescales according to ${ }^{53} \mathrm{Mn}-{ }^{53} \mathrm{Cr}$ systematics, Geochim. Cosmochim. Acta, 62, 28632886, 1998.

Mikouchi, T., M. Miyamoto, and G. A. McKay, Mineralogical study of angrite Asuka-881371: Its possible relation to angrite LEW 87051, Proc. NIPR Symp. Antarctic Meteorites, 9, 174-188, 1996.

Mikouchi, T., M. Miyamoto, G. McKay, and L. Le, Cooling rate estimates of quenched angrites: Approaches by crystallization experiments and cooling rate calculations of olivine xenocrysts, Meteoritics \& Planetary Sci., 36, A134-A145, 2001.

Mikouchi, T., G. McKay, E. Koizumi, A. Monkawa, and M. Miyamoto, Northwest Africa 1670: A new quenched angrite, Meteoritics \& Planetary Sci., 38, A115, 2003.

Mittlefehldt, D. W., M. Killgore, and M. T. Lee, Petrology and geochemistry of D'Orbingy, geochemistry of Sahara 99555, and the origin of angrites, Meteoritics \& Planetary Sci., 37, 345-369, 2002.

Miura, Y. N., N. Sugiura, M. Kusakabe, and K. Nagao, Noble gases in Northwest Africa 1670, a new angrite, and oxygen isotopes of this angrite and some achondrites, Antarctic Meteorites, XXVIII, 50-51, 2004

Nyquist, L. E., C. Y. Shih, H. Wiesmann, and T. Mikouchi, Fossil ${ }^{26} \mathrm{Al}$ and ${ }^{53} \mathrm{Mn}$ in D'Orbigny and Sahara 99555 and the timescale for angrite magmatism, Lunar Planet. Sci., XXXIV, 1388.pdf, 2003.

Spivak-Birndorf, L., M. Wadhwa, and P. E. Janney, ${ }^{26} \mathrm{Al}-{ }^{26} \mathrm{Mg}$ chronology of the D'Orbigny and Sahara 99555 angrites, Meteoritics \& Planetary Sci., 38, 5097.pdf, 2005.

Sugiura, N., Mn-Cr chronology of olivine in some meteorites, Lunar Planetary Sci., XXXIII, 1435.pdf, 2002.

Sugiura, N., K. Hashizume, A. Miyazaki, and K. Yanai, Mn-Cr ages of two angrites, in Evolution of Solar System Materials: A New Perspective from Antarctic Meteorites, p. 131, 2003.

Sugiura, N. and H. Hoshino, Mn-Cr chronology of five IIIAB iron meteorites, Meteoritics \& Planetary Sci., 38, 117-143, 2003.

Yanai, K., Angrite Asuka-881371: Preliminary examination of a unique meteorite in the Japanese collection of Antarctic meteorites, Proc. NIPR Symp. Antarctic Meteorites, 7, 30-41, 1994.

N. Sugiura (e-mail: sugiura@eps.s.u-tokyo.ac.jp), A. Miyazaki, and K. Yanai 